OPEN ACCESS

Edited by:

Jean-Paul Janssens, Geneva University Hospitals (HUG), Switzerland

Reviewed by: Frédéric Lofaso, Hôpital Raymond-Poincaré, France Pai-Chien Chou,

Taipei Medical University Hospital, Taiwan

*Correspondence:

Alain Boussuges

alain.boussuges@univ-amu.fr; alain.boussuges@gmail.com

Specialty section: This article was submitted to Pulmonary Medicine,

a section of the journal Frontiers in Medicine

Received: 16 July 2021 Accepted: 04 October 2021 Published: 27 October 2021

Citation:

Boussuges A, Rives S, Finance J, Chaumet G, Vallée N, Risso J-J and Brégeon F (2021) Ultrasound Assessment of Diaphragm Thickness and Thickening: Reference Values and Limits of Normality When in a Seated Position. Front. Med. 8:742703 doi: 10.3389/fmed.2021.742703

\section{Ultrasound Assessment of Diaphragm Thickness and Thickening: Reference Values and Limits of Normality When in a Seated Position}

\author{
Alain Boussuges ${ }^{1,2,3 *}$, Sarah Rives ${ }^{1,2}$, Julie Finance ${ }^{3}$, Guillaume Chaumet ${ }^{4}$, \\ Nicolas Vallée ${ }^{1}$, Jean-Jacques Risso ${ }^{1}$ and Fabienne Brégeon ${ }^{3}$ \\ ${ }^{1}$ ERRSO, Institut de Recherche Biomédicale des Armées (IRBA), Toulon, France, ${ }^{2}$ Center for Cardiovascular and Nutrition \\ Research (C2VN), Aix Marseille Université, INSERM, INRAE, Marseille, France, ${ }^{3}$ Service d'Explorations Fonctionnelles \\ Respiratoires, CHU Nord, Assistance Publique des Hôpitaux de Marseille et Aix Marseille Univ, IRD, APHM, MEPHI, \\ IHU-Méditerranée Infection, Marseille, France, ${ }^{4}$ ALTRA BIO SA, Lyon, France
}

Background: Diagnosing diaphragm dysfunction in the absence of complete paralysis remains difficult. The aim of the present study was to assess the normal values of the thickness and the inspiratory thickening of both hemidiaphragms as measured by ultrasonography in healthy volunteers while in a seated position.

Methods: Healthy volunteers with a normal pulmonary function test were recruited. The diaphragmatic thickness was measured on both sides at the zone of apposition of the diaphragm to the rib cage during quiet breathing at end-expiration, end-inspiration, and after maximal inspiration. The thickening ratio, the thickening fraction, and the thickness at end-inspiration divided by the thickness at deep breathing were determined. The mean values and the lower and upper limits of normal were determined for men and women.

Results: 200 healthy volunteers (100 men and 100 women) were included in the study. The statistical analysis revealed that women had a thinner hemidiaphragm than men on both sides and at the various breathing times studied. The lower limit of normality of the diaphragm thickness measured at end-expiration was estimated to be $1.3 \mathrm{~mm}$ in men and $1.1 \mathrm{~mm}$ in women, on both sides. The thickening fraction did not differ significantly between men and women. In men, it ranged from 60 to $260 \%$ on the left side and from 57 to $200 \%$ on the right side. In women, it ranged from 58 to $264 \%$ on the left side and from 60 to $229 \%$ on the right side. The lower limits of normality of the thickening fraction were determined to be 40 and 39\% in men and 39 and 48\% in women for the right and left hemidiaphragms, respectively. The upper limit for normal of the mean of both sides of the ratio thickness at end-inspiration divided by the thickness at deep breathing was determined to be 0.78 in women and 0.79 in men.

Conclusion: The normal values of thickness and the indexes of diaphragmatic function should help clinicians with detecting diaphragm atrophy and dysfunction.

Keywords: chest ultrasonography, hemidiaphragm, thickening fraction, thickening ratio, respiratory maneuvers 


\section{INTRODUCTION}

Measurement of the diaphragm thickness at the zone of apposition of the diaphragm to the rib cage has been used to detect diaphragm paralysis (1). It has been reported that a paralyzed diaphragm does not thicken significantly or become thinner upon deep inspiration compared with the thickness at end-expiration. A threshold of $20 \%$ is accepted by most authors for the diagnosis of hemidiaphragm paralysis (2). Diaphragm dysfunction in the absence of complete paralysis remains difficult to diagnose, however. Detection of such dysfunction is important because, although unilateral diaphragm weakness can remain asymptomatic in some patients, it can negatively impact the quality of life in some subjects, in particular those with underlying obesity or cardiorespiratory diseases. In this context, various clinical conditions such as orthopnea, coughing, chest pain, dyspnea on exertion, or sleep-disordered breathing can be observed $(3,4)$. Lastly, impairment of diaphragmatic function is a marker of disease severity in a number of neurological and muscular diseases such as amyotrophic lateral sclerosis (ALS), Duchenne muscular dystrophy (DMD), myotonic dystrophy, and myasthenia gravis (5).

A diagnostic approach of diaphragm dysfunction could be provided based on the lower limit value of normality of thickness and thickening. Several studies have determined the normal values of thickness measured at end-expiration and at endinspiration in healthy volunteers in a supine position (6-10). To assess the quality of diaphragmatic function, the thickening ratio (TR) i.e., the thickness at end-inspiration divided by the thickness at end-expiration has been determined. The normal value for the TR has been estimated to be between 1.7 and 2 $(6,7,9,11)$. In some subjects, such as patients suffering from respiratory failure secondary to pulmonary or neuro-muscular diseases, the supine position is not well tolerated. Furthermore, it has been demonstrated that both the diaphragm thickness (12) and inspiratory thickening (13) are greater in sitting and standing positions than in the supine position.

By studying 45 healthy subjects, Brown et al. (13) determined that the normal percentage of thickening (the ratio of thickness at end-inspiration-thickness at end-expiration divided by thickness at end-expiration) was $65 \%$ when supine, $97 \%$ when seated and $174 \%$ when standing. Consequently, the lower limit of normal determined from studies performed in the supine position cannot be used when patients are placed in a seated position. Few authors have studied volunteers in semi-recumbent, recumbent, or sitting positions (13-15). Accurate normal values cannot be determined from these studies. Indeed, although it is recognized that gender and side have an impact on diaphragm thickness, in these previous studies the methods were not designed to determine normal values in men and women for both hemidiaphragms.

Lastly, the ratio between diaphragm thickness at the end of tidal volume and the diaphragm thickness at maximal inspiration ( $\Delta$ Tmax) has been proposed by Fantini et al. (16) to detect impairment in pulmonary function tests and as an indication for mechanical ventilation support in patients suffering from ALS. Indeed, the $\Delta T \max$ has been related to respiratory function tests (17). Although this ratio might be a relevant index of diaphragmatic function, to date, the normal values have been only estimated based on a small sample.

The present study was designed to determine the normal values of diaphragmatic thicknesses and the indexes of diaphragmatic function such as the thickening ratio and the $\Delta$ Tmax based on a large population of healthy volunteers of both genders investigated while in a seated position.

\section{MATERIALS AND METHODS}

To recruit healthy volunteers, weekly medical consultations were conducted from January 2019 to January 2021. The research was conducted according to the Helsinki Declaration. The study protocol was approved by the Ethics Committee of Aix Marseille University (CPPRB 1, NoA01299-32). Written informed consent was obtained from all healthy volunteers. The volunteers were non-smokers and did not suffer from sarcopenia or morbid obesity. They were considered to be healthy if they did not have a history of cardio-respiratory disease or thoracic trauma and no clinical impairments at the time of the examination. Volunteers were sedentary or occasionally engaged in recreational sports activities, no athletes with a high level of physical training was included in the study. Furthermore, the pulmonary function test of the volunteers had to be normal. Pulmonary function was assessed with a spirometer (Ilmeter 1,304; Masterlab Jaeger, Wurzberg, Germany) according to the ERS/ATS standards (18). The criteria for classifying a pulmonary function test as normal were a slow vital capacity (SVC), forced vital capacity (FVC), and forced expiratory volume in $1 \mathrm{~s}$ (FEV 1) higher than the lower limit of normal of the reference population and a FEV1 to VC ratio greater than 0.7 . Lastly, the diaphragmatic motion of both hemidiaphragms during quiet breathing and deep breathing was recorded in all of the volunteers using M-mode ultrasonography. Ultimately, to include the volunteers, the excursions had to be greater than the recently published lower limits of normality (19).

\section{Calculation of the Sample}

Previous studies have reported that diaphragmatic thickness is greater in healthy men than in healthy women. To find differences between genders and appropriate normal values for men and women, the calculation of the sample was based on the results of Cardenas et al. (14) as this study used the same measurement method as ours. These authors reported a diaphragm thickness at the end of expiration of $1.9 \pm 0.3 \mathrm{~mm}$ in men and $1.79 \pm 0.3 \mathrm{~mm}$ in women. For a $0.05 \%$ alpha risk and an $80 \%$ power, we determined that at least 92 subjects would have to be included in each group (men and women). Since measurement of the diaphragm thickness can be difficult to perform on both sides in some volunteers, to increase the accuracy of the results, we aimed for a sample of 100 volunteers in both groups.

\section{Ultrasound Examinations}

The ultrasound examinations were carried out by two experienced investigators using a commercially available Doppler echocardiograph (Vivid S60N, GE Healthcare, Milwaukee, Wl, USA) connected to a linear vascular transducer (9L probe). The volunteers were studied on a chair, head 
and trunk aligned vertically and with hips and knees flexed at $90^{\circ}$. The trunk angle, i.e., the angle between the trunk and the horizontal axis through the trochanter, was around $90^{\circ}$. The diaphragmatic thicknesses were assessed by B-mode ultrasonography according to a previously published method $(6,7)$. Briefly, both hemidiaphragms were visualized at the zone of apposition, and the probe was placed below the phrenicocostal sinus near the anterior or the mid-axillary line at the eighth or the ninth intercostal space. The diaphragm was identified as a three-layered structure with two parallel echogenic lines, the diaphragmatic pleura and the peritoneal fascia, enclosing the hypoechoic diaphragmatic muscle. A third hyperechoic line was frequently seen in the middle of the non-echogenic layer, considered to be the fibrous layer in the center of the diaphragm. The intercostal space that provided the best visualization of the diaphragm was chosen and the probe was positioned as the two facial lines outlining the diaphragm were parallel. The thickness of each hemidiaphragm was directly measured from the frozen B-mode images (Figure 1). The diaphragm thickness was measured as the distance from the middle of the pleural membrane to the middle of the peritoneal membrane $(14,20,21)$. The measurements were performed at the end of expiration (functional residual capacity), at the end of inspiration during quiet breathing at tidal volume (Figure 2), and after deep breathing at total lung capacity (TLC). Measurements were averaged from at least three different breathing cycles. All of the examinations were recorded for subsequent blind analysis. The percentage of thickening i.e., the ratio: thickness at endinspiration-thickness at end-expiration divided by thickness at end-expiration, was determined for both hemidiaphragms for quiet breathing (at tidal volume) and maximal inspiration (at TLC). The ratio between the diaphragm thickness at the end of tidal volume and the diaphragm thickness at maximal inspiration $(\Delta \operatorname{Tmax})$ was also calculated.

\section{Statistical Analysis}

The results are reported as mean \pm SD [lower limit of normal (LLN)-upper limit of normal (ULN)]. The lower and the upper limits of normal were calculated as means $\pm 1.95 \mathrm{SD}$. A linear regression analysis was carried out to probe for an association of the ultrasonographic measurements with gender, age, and body mass index. Statistical tests were performed with $\mathrm{R}$ statistical software. The significance level was $p<0.05$.

\section{RESULTS}

To begin with, 216 healthy subjects were screened. However, 16 subjects could not be included because of lower spirometry parameters than normal, a poor echographic image quality, or a prior thoracic trauma. Two hundred healthy volunteers (100 men and 100 women) were ultimately included in the study. The characteristics of the healthy volunteers who were assessed are presented in Table 1.

Tables 2, 3 list the results of the diaphragmatic thicknesses measured in men and women on the right and the left side, respectively.
As expected, greater thicknesses were recorded in men compared to women on both sides and at the various breathing times studied, i.e., at end-expiration, end-inspiration during quiet breathing, and deep inspiration.

The right-to-left ratio of the thickness measured at endexpiration was $\sim 1$ and it was similar for both genders $(1.1 \pm 0.2$ [0.7-1.5] in men and $1.1 \pm 0.3$ [0.6-1.6] in women.

The differences in the thicknesses measured at end-expiration for both sides were small and not significantly different in men $(0.3 \pm 0.3 \mathrm{~mm}[0-0.9])$ vs. women $(0.3 \pm 0.3 \mathrm{~mm}[0-1])$ The upper limit of normality in the difference of the thickness between the two sides was determined to be $0.9 \mathrm{~mm}$ in men and $1 \mathrm{~mm}$ in women.

The percentage of thickening at quiet breathing was similar in men and women. In the same individual, the difference in the percentage of thickening between the two sides was determined to be $13 \pm 11 \%[0-34]$ in men and $16 \pm 13 \%$ [0-41] in women. In some of the volunteers, the same percentage of thickening was recorded on both sides but in other subjects, the difference could be as much as $54 \%$.

The percentage of thickening at deep breathing was not significantly different between men and women. In men, it ranged from 60 to $260 \%$ on the left side and from 57 to $200 \%$ on the right side. In women, the percentage of thickening at deep breathing ranged from 58 to $264 \%$ on the left side and from 60 to $229 \%$ on the right side. In the same individual, the difference between the two sides in the percentage of thickening at deep breathing, was $29 \pm 23 \%$ [0-75] in men and $35 \pm 29 \%$ [0-92] in women.

The mean $\Delta$ Tmax of both sides was calculated to be 0.64 \pm 0.07 in men and $0.63 \pm 0.08$ in women. The upper limit of normality was calculated to be 0.79 in men and 0.78 in women. A number of healthy volunteers ( 20 women and 20 men) had a $\Delta$ Tmax greater than 0.75 on one hemidiaphragm (right or left). By contrast, only one volunteer (a woman) out of 200 had a $\Delta$ Tmax greater than 0.75 on both sides.

The results of the linear regression analysis correlation are presented in Table 4.

\section{DISCUSSION}

This study determined the normal values of diaphragmatic thickness and the indices of contractility based on a large population of men and women assessed while in a seated position.

As suggested by previous studies $(6,7,14)$ women had a thickness at end-expiration that was thinner than that of men. This indicates that gender-specific normal values should be used.

In our study, the lower limits of normality of the diaphragm thickness measured at end-expiration were estimated to be $1.1 \mathrm{~mm}$ in women and $1.3 \mathrm{~mm}$ in men on both sides. These values are close to the results of Cardenas et al. (14). Based on assessment of 64 healthy volunteers, these authors reported a lower limit of normality of the right hemidiaphragm of $1.23 \mathrm{~mm}$ in women and $1.25 \mathrm{~mm}$ in men. These thresholds should be useful for assessment of the quality of the diaphragm muscle 


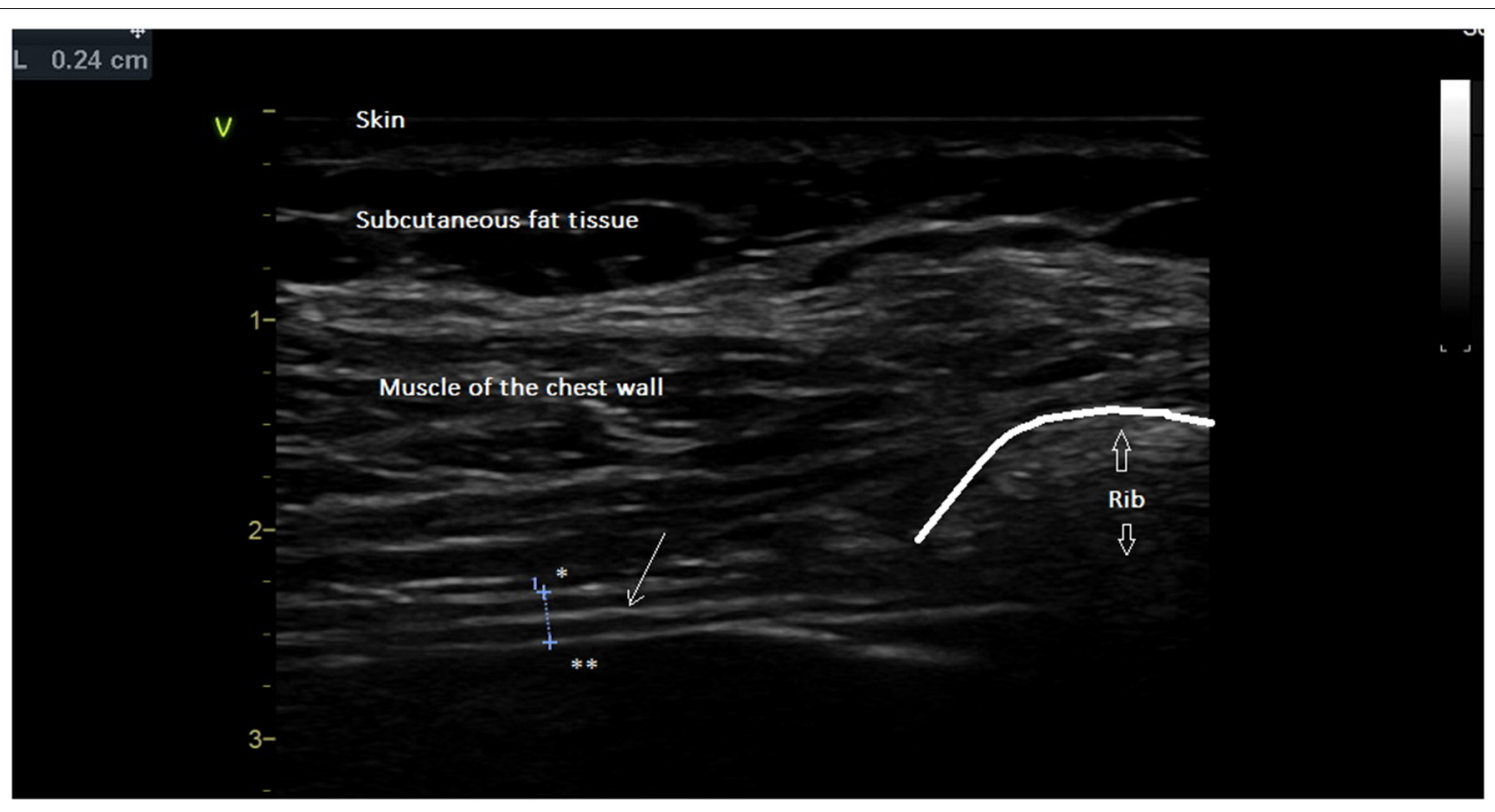

FIGURE 1 | Diaphragm thickness at end-expiration $(L=0.24 \mathrm{~cm})$ was measured from the middle of the pleural line * to the middle of the peritoneal line ${ }^{* \star}$. Thin arrow $=$ fibrous center line. Large arrow $=$ acoustic shadow generated by rib.

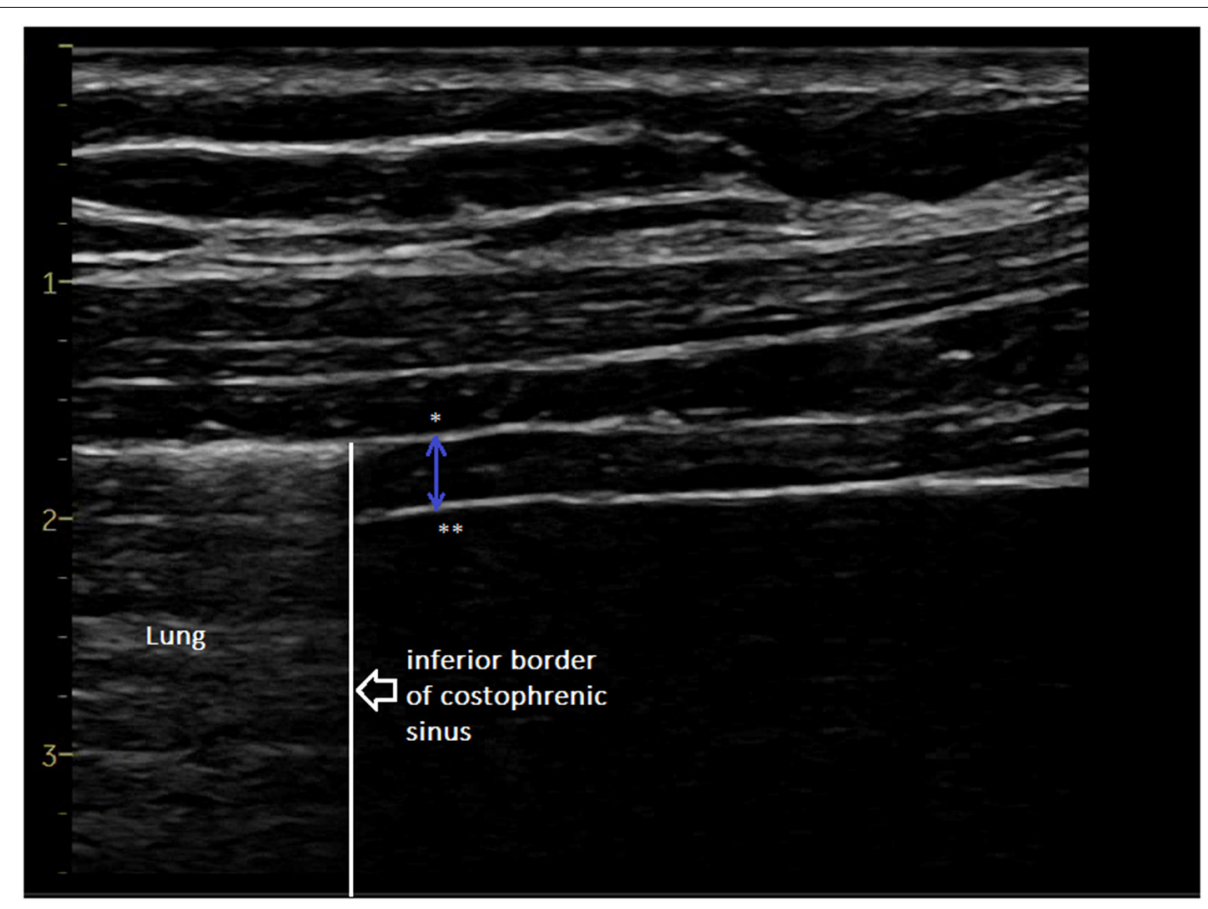

FIGURE 2 | Diaphragm thickness at end-inspiration measured from the middle of the pleural line * to the middle of the peritoneal line **. Additional file: video reporting the changes in diaphragm thickness during the breathing cycle (increase in diaphragm thickness at inspiration).

and to detect atrophy induced by muscle wasting, neuromuscular disease, or hemidiaphragm paralysis $(1,22-25)$.

To estimate the quality of the diaphragm function it can be also instructive to compare the thickness of both sides measured at end-expiration by means of the right-to-left ratio. Boon et al.
(6) have reported that one side is frequently thicker than the other in healthy volunteers, but that the difference between the two sides should be small in normal subjects. In our population, the difference between the two sides was small in men and women (a mean of $0.3 \mathrm{~mm}$ ). The ratio of the thickness of both 
TABLE 1 | Study population: anthropometric data, pulmonary function tests and excursions of both hemidiaphragms recorded by M-mode ultrasonography.

\begin{tabular}{|c|c|c|}
\hline & $\begin{array}{c}\text { Men } \\
\text { Mean } \pm \text { SD }\end{array}$ & $\begin{array}{c}\text { Women } \\
\text { Mean } \pm \text { SD }\end{array}$ \\
\hline Age (years) & $51 \pm 16$ & $52 \pm 16$ \\
\hline Height (cm) & $177 \pm 7$ & $163 \pm 7$ \\
\hline Weight (kg) & $79 \pm 12$ & $67 \pm 13$ \\
\hline $\mathrm{BMI}\left(\mathrm{kg} / \mathrm{m}^{2}\right)$ & $25 \pm 5$ & $25 \pm 5$ \\
\hline $\begin{array}{l}\text { SVC }(L),(\text { percentage of } \\
\text { predicted \%) }\end{array}$ & $4.6 \pm 0.9(102 \pm 11)$ & $3.5 \pm 0.9(106 \pm 13)$ \\
\hline $\begin{array}{l}\text { FVC }(\mathrm{L}),(\text { percentage of } \\
\text { predicted \%) }\end{array}$ & $4.6 \pm 0.9(101 \pm 11)$ & $3.4 \pm 1(104 \pm 14)$ \\
\hline $\begin{array}{l}\text { FEV }(L) \text {, (percentage of } \\
\text { predicted \%) }\end{array}$ & $3.7 \pm 0.7(101 \pm 11)$ & $2.7 \pm 0.8(100 \pm 12)$ \\
\hline FEV / FVC ratio (\%) & $80 \pm 6$ & $81 \pm 6$ \\
\hline $\begin{array}{l}\text { Right excursion-quiet } \\
\text { breathing }(\mathrm{cm})\end{array}$ & $2 \pm 0.5$ & $1.9 \pm 0.5$ \\
\hline $\begin{array}{l}\text { Right excursion-voluntary } \\
\text { sniffing }(\mathrm{cm})\end{array}$ & $2.7 \pm 0.7$ & $2.3 \pm 0.7$ \\
\hline $\begin{array}{l}\text { Right excursion-deep } \\
\text { breathing }(\mathrm{cm})\end{array}$ & $6 \pm 0.9$ & $5 \pm 0.9$ \\
\hline $\begin{array}{l}\text { Left excursion-quiet } \\
\text { breathing }(\mathrm{cm})\end{array}$ & $2.2 \pm 0.6$ & $1.9 \pm 0.5$ \\
\hline $\begin{array}{l}\text { Left excursion - voluntary } \\
\text { sniffing }(\mathrm{cm})\end{array}$ & $2.8 \pm 0.8$ & $2.4 \pm 0.6$ \\
\hline $\begin{array}{l}\text { Left excursion-deep } \\
\text { breathing (cm) }\end{array}$ & $6.2 \pm 0.9$ & $5 \pm 0.7$ \\
\hline
\end{tabular}

BMI, body mass index; SVC, slow vital capacity; FVC, forced vital capacity; FEV1, forced expiratory volume in $1 \mathrm{~s}$.

sides in patients with normal diaphragmatic function should be between 0.7 and 1.5 in men and between 0.6 and 1.6 in women. Furthermore, the upper limit of normality for the differences between sides was determined to be $1 \mathrm{~mm}$ in women and $0.9 \mathrm{~mm}$ in men. These thresholds can be used to detect a degree of imbalance between the two hemidiaphragms.

It has been shown that the use of indexes such as inspiratory thickening can be used to detect diaphragm dysfunction. In our work, the mean percentage of thickening during quiet breathing was determined to be between 30 and $35 \%$ on both sides in men and women, which is close to the results of Thimmaiah et al. (26).

As previously reported (27), a considerable degree of variability of thickening between the two sides has been noted. In our population, the mean difference in the percentage of thickening between the two sides was determined to be $13 \%$ in men and $16 \%$ in women. Although in some of the volunteers the same percentage of thickening was noted on both sides, in one woman the difference was nearly $54 \%$. The upper limit of normality for the percentage of thickening at quiet breathing was determined to be between 57 and 67\% according to the side and the gender. This value should be useful to detect an increase in the work of breathing at baseline. For example, this increase can be observed on one side in patients suffering from contralateral hemidiaphragm dysfunction (28). In such circumstances, the compensatory mechanism includes an increase in neural drive to the functioning hemidiaphragm (29)
TABLE 2 | Study of the right hemidiaphragm.

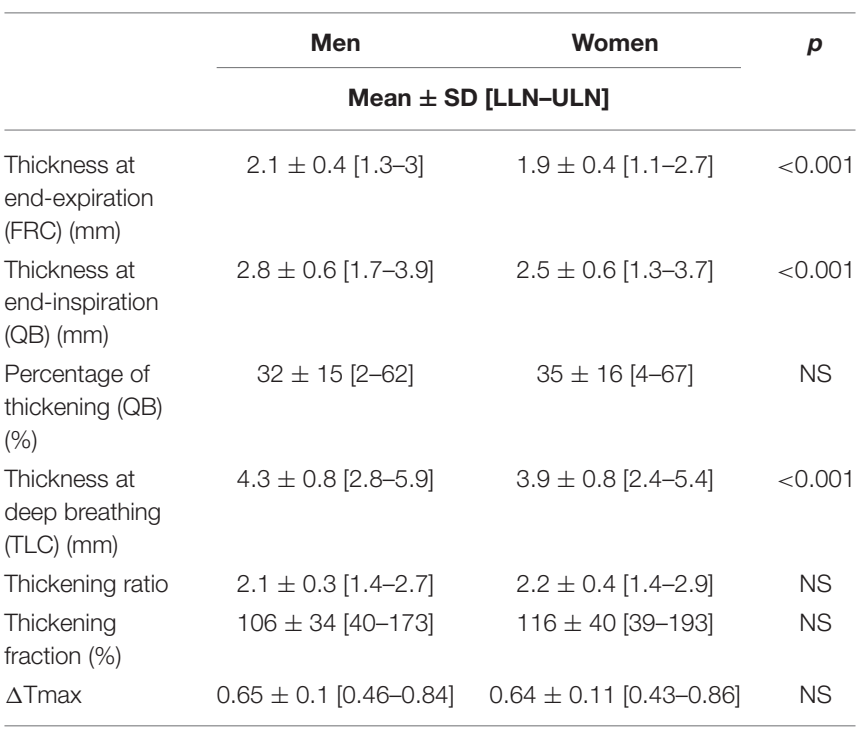

FRC, functional residual capacity; QB, quiet breathing; TLC, total lung capacity; LLN, lower limit of normality; ULN, upper limit of normality; $\triangle T$ max, ratio between diaphragm thickness at the end of tidal volume and diaphragm thickness at maximal inspiration.

TABLE 3 | Study of the left hemidiaphragm.

\begin{tabular}{lccc}
\hline & Men & Women & p \\
\cline { 2 - 3 } & \multicolumn{1}{c}{ Mean \pm SD [LLN-ULN] } & \\
\cline { 2 - 3 } $\begin{array}{l}\text { Thickness at } \\
\text { end-expiration } \\
\text { (FRC) } \\
\text { (mm) }\end{array}$ & $2 \pm 0.4[1.3-2.7]$ & $1.7 \pm 0.3[1.1-2.4]$ & $<0.001$ \\
$\begin{array}{l}\text { Thickness at } \\
\text { end-inspiration }\end{array}$ & $2.6 \pm 0.5[1.7-3.5]$ & $2.3 \pm 0.5[1.3-3.3]$ & $<0.001$ \\
$\begin{array}{l}\text { (QB) } \\
\text { (mm) }\end{array}$ & & & \\
$\begin{array}{l}\text { Percentage of } \\
\text { thickening (QB) } \\
\text { (\%) }\end{array}$ & $30 \pm 14[4-57]$ & $33 \pm 15[3-62]$ & NS \\
$\begin{array}{l}\text { Thickness at } \\
\text { deep breathing } \\
\text { (TLC) (mm) }\end{array}$ & $4.2 \pm 0.8[2.6-5.8]$ & $3.8 \pm 0.8[2.3-5.3]$ & $<0.001$ \\
$\begin{array}{l}\text { Thickening ratio } \\
\text { Thickening }\end{array}$ & $2.1 \pm 0.4[1.4-2.8]$ & $2.2 \pm 0.4[1.5-2.9]$ & NS \\
fraction (\%) & $112 \pm 37[39-184]$ & $121 \pm 37[48-193]$ & NS \\
$\Delta$ Tmax & $0.63 \pm 0.1[0.45-0.8]$ & $0.61 \pm 0.1[0.43-0.79]$ & NS \\
\hline
\end{tabular}

FRC, functional residual capacity; $Q B$, quiet breathing; TLC, total lung capacity; LLN, lower limit of normality; ULN, upper limit of normality; $\triangle$ Tmax, ratio between diaphragm thickness at the end of tidal volume and diaphragm thickness at maximal inspiration.

leading to an increase in muscular activity. The high degree of variability in the percentage of thickening during quiet breathing is the reason why in our population the lower limits of normality for the percentage of thickening during quiet breathing were close to 0 for men and women on both sides. The relevance of the assessment of the percentage of thickening during quiet breathing to assess diaphragmatic function has been questioned. Indeed, based on assessment of 150 healthy volunteers, Harper 
TABLE 4 | Linear regression analysis assessing the association between the diaphragmatic thickness and the demographic and the BMl data.

\begin{tabular}{lllllllll}
\hline & \multicolumn{3}{l}{ Thickness (FRC) } & \multicolumn{2}{l}{ Thickness (TLC) } & \multicolumn{2}{l}{ Thickening fraction } \\
\cline { 2 - 6 } & Left & Right & Left & Right & Left & Right \\
\hline Gender (male) & $<0.001$ & $<0.001$ & $<0.001$ & $<0.0005$ & NS & NS \\
Age & NS & NS & NS & NS & NS & NS \\
BMl & $<0.05$ & NS & NS & NS & NS & NS \\
\hline
\end{tabular}

FRC, functional residual capacity; TLC, total lung capacity; BMI, Body Mass Index.

et al. (27) reported that in some healthy subjects (29\% of the hemidiaphragms investigated) the percentage of thickening was less than $10 \%$ during tidal breathing. In three volunteers, a lack of thickening was observed on one side. In our population, the percentage of thickening at quiet breathing was less than $10 \%$ in five cases. Consequently, it is not possible to use the measurement of the thickening during quiet breathing to diagnose hemidiaphragm paralysis.

The use of the percentage of thickening at deep inspiration is recognized to be a better tool to detect hemidiaphragm paralysis. In our work, the thickening fraction was determined to range from 2.1 to 2.2 according to the side and gender. These results are in agreement with previous studies $(9,11,14)$. Furthermore, the thickening fraction was $\sim 100 \%$ in men and women, which is close to what was found in the study of Brown et al. (13) involving 45 healthy volunteers who were assessed while in a seated position. In contrast, these authors reported a lower mean thickening fraction in the same population when they were assessed while in a supine position $(\sim 60 \%)$.

To detect diaphragm dysfunction in the absence of complete paralysis, the lower limits of normality were assessed in our population. For the thickening ratio, the lower limit of normality was 1.4 in men on both sides. In women, the lower limit of normality was 1.4 on the right side and 1.5 on the left side.

For the thickening fraction, the thresholds were 35-38\% in men and $35-47 \%$ in women for the right and the left hemidiaphragm, respectively. The lower limits of normality were calculated from the mean $\pm 1.95 \mathrm{SD}$, as recommended. Since there was a high degree of variability in our study in the thickening fraction between individuals, the thresholds may have been underestimated. In the whole population, no thickening fraction of less than $57 \%$ was observed. Consequently, a percentage of thickening greater than the LLN but lower than $57 \%$ should be considered as to be abnormally low.

In our results, the large range in the percentage of thickening suggested that various individual characteristics and probably technical aspects, such as the quality of the respiratory maneuver, the ultrasound image quality and the position of the probe, had an impact on the measurement of this parameter. In this context, it is not surprising that previous works have reported a poor correlation between the strength generated by the diaphragm, estimated by the transdiaphragmatic pressure, and the percentage of thickening (30). Further works would be interesting on this topic.

The ratio between the inspiratory thickness at quiet inspiration and the inspiratory thickness at deep breathing
( $\Delta$ Tmax) provides informations regarding the work of breathing at rest compared to the maximal work of breathing. A low ratio indicates a good capacity for the subject to increase the work of breathing (17). In contrast, a $\Delta T$ max close to one suggests that the reserve of the increase in the work of breathing is minimal. In our work, the mean $\Delta$ Tmax was determined to be 0.6 . Fantini et al. (17) have reported that a $\Delta$ Tmax greater than 0.75 , is associated with an impairment in pulmonary function testing in ALS patients and an indication for mechanical ventilation support. When the $\Delta \mathrm{Tmax}$ is greater than 0.75 , it provides $75 \%$ sensitivity and $85 \%$ specificity for predicting an FVC value lower than $50 \%$ of the predicted value. In our population, a $\Delta$ Tmax greater than 0.75 at rest on one side could be observed in a number of the volunteers (40 out of 200 subjects). In patients, with an increase in the work of breathing at rest, the two hemidiaphragms should be stimulated. Consequently, for accurate detection of the limitation of the increase in the work of breathing, it would be better to measure the $\Delta$ Tmax on both sides. In our population, a $\Delta \mathrm{Tmax}$ greater than 0.75 on both sides was observed in just one out of 200 volunteers. Furthermore, the determination of the mean $\Delta$ Tmax of both sides should be informative. The upper limit for a normal mean $\Delta$ Tmax was determined to be 0.78 in men and 0.79 in women.

The values determined in our work should only be used in patients assessed with the same procedure, i.e., in patients while seated and using the same method of measurements.

It has been reported that the hemidiaphragm thickness varies depending on which intercostal space is chosen, with hemidiaphragms being thicker at the lower intercostal space (6). In our work, the measurements performed on the intercostal space i.e., the $8^{\text {th }}$ or the $9^{\text {th }}$, provided the best image quality. It is not certain that the diaphragm thickness was systematically measured at the lower intercostal space, with an impact on the normal values proposed for the thickness at end-expiration and inspiration. Consequently, in clinical practice, when the measurements indicate a thin hemidiaphragm, it would be interesting to try a lower approach in an effort to confirm the limited thickness of the hemidiaphragm.

Furthermore, in this work, we chose to perform the measurements on BD images. There is no standardized approach for the measurement of diaphragm thickness. Some authors recommended the use of $\mathrm{B}$-mode $(6,11)$ whereas other authors have used M-mode (15). It was recently reported that there is a good degree of agreement between both methods (31). Based on our experience in cardiac and vascular investigations, we believe that $\mathrm{B}$-mode is preferable to $\mathrm{M}$ mode. Indeed, to obtain a reliable measurement of the thickness it is important that the calipers are placed perpendicular to the hemidiaphragms. During breathing, cyclical motion of the diaphragm and the resulting changes in M-mode cursor location can result in a loss of perpendicularity of the M-line on the hemidiaphragm and hence a degree of error in the thickness measurement.

The limit values of normality of the thickness and the indexes of function of both hemidiaphragms reported in the present study should be useful to detect diaphragmatic dysfunction in 
the absence of complete paralysis. To the best of our knowledge, these thresholds are the first to have been determined with a large population of healthy volunteers of both genders while in a seated position. These findings are likely to be useful for guiding therapeutic management such as respiratory physiotherapy or the initiation of ventilatory support.

\section{DATA AVAILABILITY STATEMENT}

The raw data supporting the conclusions of this article will be made available by the authors, without undue reservation.

\section{ETHICS STATEMENT}

The studies involving human participants were reviewed and approved by Aix Marseille University, CPPRB 1, NoA01299-32. The patients/participants provided their written informed consent to participate in this study.

\section{AUTHOR CONTRIBUTIONS}

$\mathrm{AB}$ and FB conceived and designed the study. SR, NV, J-JR, and JF assisted with the technical aspects of the protocol, recruited

\section{REFERENCES}

1. Gottesman E, McCool FD. Ultrasound evaluation of the paralyzed diaphragm. Am J Respir Crit Care Med. (1997) 155:15704. doi: 10.1164/ajrccm.155.5.9154859

2. Boussuges A, Rives S, Finance J, Brégeon, F. Assessment of diaphragmatic function by ultrasonography: current approach and perspectives. World J Clin Cases. (2020) 8:2408-24. doi: 10.12998/wjcc.v8.i12.2408

3. Hart N, Nickol AH, Cramer D, Ward SP, Lofaso F, Pride NB, et al. Effect of severe isolated unilateral and bilateral diaphragm weakness on exercise performance. Am J Respir Crit Care Med. (2002) 165:126570. doi: $10.1164 / \mathrm{rccm} .2110016$

4. Steier J, Jolley CJ, Seymour J, Kaul S, Luo YM, Rafferty GF, et al. Sleepdisordered breathing in unilateral diaphragm paralysis or severe weakness. Eur Respir J. (2008) 32:1479-87. doi: 10.1183/09031936.00018808

5. Carrié C, Bonnardel E, Vally R, Revel P, Marthan, R. Vital capacity impairment due to neuromuscular disease and its correlation with diaphragmatic ultrasound: a preliminary study. Ultrasound Med Biol. (2016) 42:1439. doi: 10.1016/j.ultrasmedbio.2015.09.020

6. Boon AJ, Harper CJ, Ghahfarokhi LS, Strommen JA, Watson JC, Sorenson EJ, et al. Two-dimensional ultrasound imaging of the diaphragm: quantitative values in normal subjects. Muscle Nerve. (2013) 47:884-9. doi: 10.1002/mus.23702

7. Carrillo-Esper R, Pérez-Calatayud ÁA, Arch-Tirado E, Díaz-Carrillo MA, Garrido-Aguirre E, Tapia-Velazco R, et al. Standardization of sonographic diaphragm thickness evaluations in healthy volunteers. Respir Care. (2016) 61:920-4. doi: 10.4187/respcare.03999

8. Kim M, Lee K, Cho J, Lee W. Diaphragm thickness and inspiratory muscle functions in chronic stroke patients. Med Sci Monit. (2017) 23:124753. doi: 10.12659/MSM.900529

9. Zhu Z, Li J, Yang D, Gao F, Du L, Yang, et al. Ultrasonographic evaluation of diaphragm thickness and excursion in patients with cervical spinal cord injury. J Spinal Cord Med. (2019) 44:1-6. doi: 10.1080/10790268.2019.1669955

10. Spiesshoefer J, Herkenrath S, Henke C, Langenbruch L, Schneppe M, Randerath W, et al. Evaluation of respiratory muscle strength and diaphragm ultrasound: normative values, theoretical considerations, and practical recommendations. Respiration. (2020) 99:369-81. doi: 10.1159/000506016 all the participants, and were involved in the acquisition of the data. $A B$ and SR performed the ultrasound examinations. $A B$ and $G C$ analyzed the data and performed the statistical analysis. $\mathrm{AB}, \mathrm{GC}$, and $\mathrm{SR}$ have drafted the article while $\mathrm{FB}$, $\mathrm{J}-\mathrm{JR}$, and $\mathrm{NV}$ revised it critically for important intellectual content. All authors have given final approval of the version to be published.

\section{FUNDING}

This study was supported by a French Ministry of Defense research grant (Direction Générale de l'Armement, MHR-1-0723).

\section{ACKNOWLEDGMENTS}

The authors gratefully acknowledge the volunteers.

\section{SUPPLEMENTARY MATERIAL}

The Supplementary Material for this article can be found online at: https://www.frontiersin.org/articles/10.3389/fmed. 2021.742703/full\#supplementary-material

11. Baria MR, Shahgholi L, Sorenson EJ, Harper CJ, Lim KG, Strommen JA, et al. B-mode ultrasound assessment of diaphragm structure and function in patients with COPD. Chest. (2014) 146:680-5. doi: 10.1378/chest.13-2306

12. Hellyer NJ, Andreas NM, Bernstetter AS, Cieslak KR, Donahue GF, Steiner EA, et al. Comparison of diaphragm thickness measurements among postures via ultrasound imaging. PM R. (2017) 9:21-5. doi: 10.1016/j.pmrj.2016. 06.001

13. Brown C, Tseng SC, Mitchell K, Roddey T. Body position affects ultrasonographic measurement of diaphragm contractility. Cardiopulm Phys Ther J. (2018) 29:166-72. doi: 10.1097/CPT.0000000000000083

14. Cardenas LZ, Santana PV, Caruso P, Ribeiro de Carvalho CR, Pereira de Albuquerque AL. Diaphragmatic ultrasound correlates with inspiratory muscle strength and pulmonary function in healthy subjects. Ultrasound Med Biol. (2018) 44:786-93. doi: 10.1016/j.ultrasmedbio.2017.11.020

15. Scarlata S, Mancini D, Laudisio A, Raffaele AI. Reproducibility of diaphragmatic thickness measured by M-mode ultrasonography in healthy volunteers. Respir Physiol Neurobiol. (2019) 260:5862. doi: 10.1016/j.resp.2018.12.004

16. Fantini R, Tonelli R, Castaniere I, Tabbì L, Pellegrino MR, Cerri S, et al. Serial ultrasound assessment of diaphragmatic function and clinical outcome in patients with amyotrophic lateral sclerosis. BMC Pulm Med. (2019) 19:160. doi: 10.1186/s12890-019-0924-5

17. Fantini R, Mandrioli J, Zona S, Antenora F, Iattoni A, Monelli $\mathrm{M}$, et al. Ultrasound assessment of diaphragmatic function in patients with amyotrophic lateral sclerosis. Respirology. (2016) 21:932-938. doi: 10.1111/resp.12759

18. Graham BL, Steenbruggen I, Miller MR, Barjaktarevic IZ, Cooper BG, Hall GL, et al. Standardization of spirometry 2019 update. An Official American Thoracic Society and European Respiratory Society technical statement. Am J Respir Crit Care Med. (2019) 200:e70-e88. doi: 10.1164/rccm.201908-1 590ST

19. Boussuges A, Finance J, Chaumet G, Brégeon, F. Diaphragmatic motion recorded by M-mode ultrasonography: limits of normality. ERJ Open Res. (2021) 7:00714-2020. doi: 10.1183/23120541.00714-2020

20. Ueki J, De Bruin PF, Pride, NB. In vivo assessment of diaphragm contraction by ultrasound in normal subjects. Thorax. (1995) 50:115761. doi: $10.1136 /$ thx.50.11.1157 
21. Ferrari G, De Filippi G, Elia F, Panero F, Volpicelli G, Aprà, et al. Diaphragm ultrasound as a new index of discontinuation from mechanical ventilation. Crit Ultrasound J. (2014) 6:8. doi: 10.1186/2036-7902-6-8

22. Hiwatani Y, Sakata M, Miwa, H. Ultrasonography of the diaphragm in amyotrophic lateral sclerosis: clinical significance in assessment of respiratory functions. Amyotroph Lateral Scler Frontotemporal Degener. (2013) 14:12731. doi: 10.3109/17482968.2012.729595

23. Cartwright MS, Keskinyan, VS. Hemidiaphragm atrophy in muscle-specific kinase myasthenia gravis. Muscle Nerve. (2016) 54:338-9. doi: 10.1002/mus.25071

24. Guimarães-Costa R, Similowski T, Rivals I, Morélot-Panzini C, Nierat MC, Thao Bui M, et al. Human diaphragm atrophy in amyotrophic lateral sclerosis is not predicted by routine respiratory measures. European Respiratory Journal. (2019) 53:1801749. doi: 10.1183/13993003.01749-2018

25. Deniz O, Coteli S, Karatoprak NB, Pence MC, Varan HD, Kizilarslanoglu MC, et al. Diaphragmatic muscle thickness in older people with and without sarcopenia. Aging Clin Exp Res. (2021) 33:573-80. doi: 10.1007/s40520-020-01565-5

26. Thimmaiah VT, Geetha MJ, Jain KP. Evaluation of thickness of normal diaphragm by B mode ultrasound. Int J Contemp Med Res. (2016) 3:2658-60.

27. Harper CJ, Shahgholi L, Cieslak K, Hellyer NJ, Strommen JA, Boon JA, et al. Variability in diaphragm motion during normal breathing, assessed with B-mode ultrasound. J Orthop Sports Phys Ther. (2013) 43:92731. doi: 10.2519/jospt.2013.4931

28. Boussuges A, Brégeon F, Blanc P, Gil JM, Poirette L. Characteristics of the paralysed diaphragm studied by M-mode ultrasonography. Clin Physiol Funct Imaging. (2019) 39:143-9. doi: 10.1111/cpf. 12549

29. Katagiri M, Young RN, Platt RS, Kieser TM, Easton PA. Respiratory muscle compensation for unilateral or bilateral hemidiaphragm paralysis in awake canines. J Appl Physiol. (1994) 77:1972-82. doi: 10.1152/jappl.1994.77. 4.1972

30. Poulard T, Fossé Q, Gennisson JL, Niérat MC, Hogrel JY, Similowski T, et al. Diaphragm thickening fraction versus transdiaphragmatic pressure in healthy subjects and ventilated patients: a breath-by-breath analysis. ERJ Open Res. (2020) 6:14. doi: 10.1183/23120541.RFMVC-2020.14

31. Kalin BS, Gürsel G. Does it make difference to measure diaphragm function with M mode (MM) or B mode (BM)? J Clin Monit Comput. (2020) 34:124757. doi: 10.1007/s10877-019-00432-7

\section{Conflict of Interest: GC was employed by ALTRA BIO SA.}

The remaining authors declare that the research was conducted in the absence of any commercial or financial relationships that could be construed as a potential conflict of interest.

Publisher's Note: All claims expressed in this article are solely those of the authors and do not necessarily represent those of their affiliated organizations, or those of the publisher, the editors and the reviewers. Any product that may be evaluated in this article, or claim that may be made by its manufacturer, is not guaranteed or endorsed by the publisher.

Copyright (c) 2021 Boussuges, Rives, Finance, Chaumet, Vallée, Risso and Brégeon. This is an open-access article distributed under the terms of the Creative Commons Attribution License (CC BY). The use, distribution or reproduction in other forums is permitted, provided the original author(s) and the copyright owner(s) are credited and that the original publication in this journal is cited, in accordance with accepted academic practice. No use, distribution or reproduction is permitted which does not comply with these terms. 